[WASHINGTON] In a bid to reduce the theoretical risk of introducing new variant Creutzfeldt-Jakob disease (vCJD) into the United States, advisers to the US Food and Drug Administration (FDA) are considering whether to recommend that people who have spent time in Britain since 1980 should be barred from donating blood.

The FDA's Transmissible Spongiform Encephalopathies Advisory Committee voted in December by nine to six to consider recommending that the agency adopt some kind of restriction on such donors. But it did not specify how long potential donors would have had to have spent in Britain to be excluded, saying it needed more data.

Any such move, however, is likely to meet opposition from those responsible for blood banks, which are already have problems obtaining adequate supplies. According to an American Red Cross official, excluding all donors who visited or lived in Great Britain between 1984 and 1990 would reduce the US blood supply by 10.7 per cent, and more than one million new donors would be required to replace those excluded.

The years 1984-90 are considered the peak risk period for contracting vCJD through eating meat contaminated with the infectious agent that causes bovine spongiform encephalopathy ('mad cow disease'). The committee will debate the matter further and may make a formal recommendation in June. Before doing so, it will consider

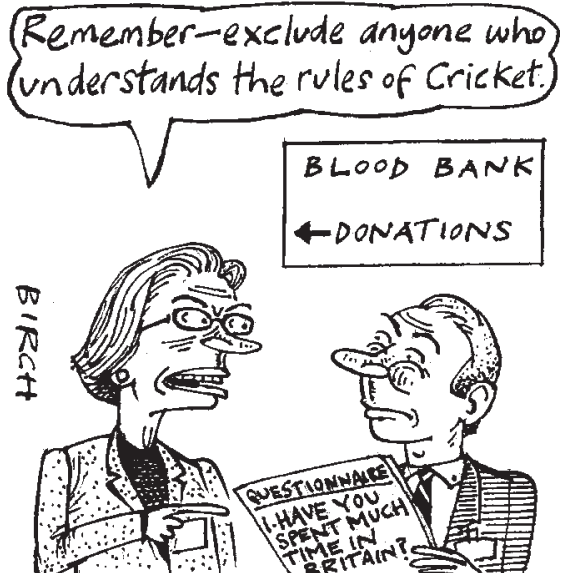

data analysing how long typical US blood donors spent in Britain in the past 19 years.

No case of vCJD has ever been attributed to blood or a blood product since the new variant disease was identified. But most committee members felt that caution was needed given that the extent of the disease in Britain is unknown, and transmission by blood remains a theoretical possibility.

So far, 35 'definite and probable' cases of vCJD have been established in Britain. If in five years Britain has 1,000 cases or more, said Paul Brown, a senior research scientist in the Laboratory of Central Nervous System Studies at the National Institute of Neurological Disorders and Stroke, who chairs the advisory committee, then adopting restrictions would be seen as "a very shrewd posture".
But representatives of blood banks at the meeting challenged this view. "The national blood supply is teetering on the brink of inadequacy," said Merlin Sayers, director of the blood bank at the Carter Blood Center in Bedford, Texas. "For us to entertain even a five per cent additional donor [loss] to prevent something which has not happened is going to be a national experiment doomed to failure, and it will jeopardize patient care."

Blood-bank officials also argued that the loss of donors would require recruiting new donors who present a small but real — rather than theoretical — risk of introducing hepatitis C or HIV into the blood supply.

Jay Epstein, the director of the FDA's Office of Blood Research and Review, conceded that it was hard to balance risks. "The problem for the FDA is that we have to factor into our thinking all the possible consequences of a change in policy," he said.

Some committee members hope that a reasonable compromise can be agreed on if the new data indicate that most travellers to Britain spent only a brief time there. A policy excluding only those who made lengthy visits would have far less impact on the US donor pool, they suggested.

"If you focus on the highest-risk people, you will get almost all of the protection and do very little to limit the supply of needed blood," says Peter Lurie, a medical researcher with the Public Citizen Health Research Group in Washington DC. Meredith Wadman

\title{
Asian scientists call on Unesco to protect indigenous knowledge
}

[BANGALORE] A group of scientists and social scientists from eight Asian nations last week called for the United Nations Educational, Scientific and Cultural Organization (Unesco) to set up a global fund to conserve and promote indigenous and civilizational knowledge systems' (ICKS).

The proposal was made at an international symposium held in Bangalore, India, as part of the preparations for the World Conference on Science in the Hungarian capital, Budapest, in the summer (see Nature 396, 299; 1998). It was sponsored jointly by Unesco and the Indian government, to focus on the social dimensions of science and technology.

Those present urged the UN body to organize two international conventions. One would focus on sustainable consumption, aimed at regulating the use of fast-eroding natural resources. The other would address the brain drain, to compensate developing nations for their loss of trained scientists and technicians to developed countries.

Researchers from China, Iran, Uzbekistan, France, the USA, Bangladesh,
Nepal, Sri Lanka and Thailand, as well as India, attended the meeting.

Officials of the National Institute of Advanced Studies (NIAS) in Bangalore, which organized the three-day meeting, said the recommendations form part of a ninepoint action plan. Delegates hope to see this included in the declaration Science agenda - a framework for action, which is expected to be adopted at Budapest.

As well as establishing a global fund for promoting ICKS, the proposals call on Unesco to design a series of projects that recognize the economic value of indigenous technologies and study how best to protect them, "leading to an international convention on protection of intellectual property rights in ICKS".

Delegates also suggested that Unesco draw up an international code of ethics for science and technology that would address a wide range of issues. These include the regulation of 'knowledge monopolies' companies or groups of companies exercising monopoly power over strategically important knowledge.
Other proposals were that Unesco should support training programmes for scientists on legal and policy issues, and for an international conference to examine the future impact of culture on science.

All these proposals will be put to the Budapest conference, together with the Bangalore communiqué: a document drawn up primarily by the Indian government which describes how society's expectations of science might be met in the 21 st century.

The Bangalore symposium adopted an amended version of Unesco's declaration on science and the use of scientific knowledge, reflecting India's concerns on traditional knowledge. (See http://helix.nature.com/wcs for a fuller report.)

In his opening speech the Indian science minister, Murli Manohar Joshi, expressed concern that information technology could create new inequalities. He urged nations to ensure that, while newly produced scientific knowledge is legally protected, "those who created and preserved various forms of traditional knowledge so faithfully over centuries are not exploited". KS Jayaraman 